\title{
Core Stability Index for Healthy Young Sri Lankan Population
}

\author{
Malwanage V.M.B.K.T* and Samita $S^{* *}$ \\ * Department of Physiotherapy, Faculty of Allied Health Sciences, University of Peradeniya \\ ${ }^{* *}$ Postgraduate Institute of Agriculture, University of Peradeniya
}

DOI: 10.29322/IJSRP.10.06.2020.p10281

http://dx.doi.org/10.29322/IJSRP.10.06.2020.p10281

\begin{abstract}
Core stability is one of the major determinants that contribute to prevent injuries, enhance performance and improve quality of life of the human. Endurance of the four major muscle groups of the central 'Core' of the human body is identified as the most reliable determinant of core stability amongst the other numerous factors which contribute to readily make one's core stability.

This study aimed to develop a 'Core Stability Index' to confer one representing value for individual's core stability based on the four endurance test scores. The study sample was consisted with the data of 400 healthy young individuals with the mean age of $23.74 \pm 1.51$ years and mean BMI (Body Mass Index) of 21.1 \pm 4.18 .

Firstly, the exploratory factor analysis was conducted to investigate the underlying structure of the association between the scores of four different endurance tests. Then the number of common factors which explains the most of the variability of the variables was estimated. Factor scores of the corresponding endurance test were also calculated to detect the regression coefficients, based on which the 'Core Stability Index' was developed. As the mean values of all the variables were significantly differ between males and males, two separate core stability indices were constructed.
\end{abstract}

Index Terms- Core stability index, core stability scoring scale, factor analysis, factor scores

\section{INTRODUCTION}

'Core stability, is considered as the muscular control required to maintain the functional stability of the human body during almost all the activities which range from simple activities of daily living to the complex activities of sports (Kisner and Colby, 2007). As it is a crucial factor for determining the stability of the spine and related structures to accomplish the functions of the human body efficiently (Crisco and Panjabi MM, 1991), improving 'Core Stability' has become one of an emerging field in the field of physiotherapy.

Many evidence suggest that the proper core stability is directly associated with the prevention of many musculoskeletal injuries and enhance the performance which ultimately leads to good quality of life (Bliven and Anderson, 2013). Since the poor core stability is a risk factor for many musculoskeletal injuries, it is important to maintain proper core stability prior to have an injury as suggested by the well-known statement "Prevention is better than cure".

For that reason, few studies have focused to implement assessment criteria for assessing and scoring the core stability of the individuals. Amongst the criterion developed by McGill et al in 2002 to interpret the mean values of four key core endurance tests is well established with strong evidence. Since it cannot be applicable to Sri Lankan population as it has developed based on the values of European population there was a thurst in developing scoring scale for core stability using the basic concepts introduce by McGill and his collages. As a result, Malwanage et al (2015) developed 08 scoring scales to measure the endurance of four key muscles which was considered to be the major reflecting component of core stability separately for males and females, 04 scales for each gender using a sample of healthy young individuals in University of Peradeniya. Since those scoring scales consider the each and every core endurance test values separately when assessing the core stability, it is difficult to obtain an overall idea about one's general core stability.

Therefore, it is felt that there is a room for implementing a statistical tool to confer one specific value for healthy young individual's core stability considering their gender and individual endurance test times.

The shortcoming that has been raised from all the scoring scales are that an individual with a salient score for few endurance tests and substandard scores for the other endurance test merely impracticable to appoint the particular individual in either category. Therefore, it is worthwhile to develop a statistical model to confer one representing value for individual's core stability mainly based on the four endurance test scores which will be a valuable tool for the physiotherapy practitioners worldwide to get an idea on the state of the core stability.

Once the individual knows their own core stability measure, they can get further measures to improve the core stability if it is 
substandard, or either could get measures to maintain the core stability if they have had a salient score in the overall core stability with the guidance of physiotherapy professionals.

\subsection{Study Sample}

\section{METHODOLOGY}

Data of 400 undergraduates with the mean age of 23.74 \pm 1.51 years and mean BMI (Body Mass Index) of $21.1+\_4.18$ were used as the studying sample. The endurance times for four different endurance tests were recorded in each student. The following formula of the proportional allocation of stratified random sampling method was used to calculate the sample size since the variance of individual strata cannot be obtained due to lack of information on individual data of the population.

Where:

$$
n_{o}=\frac{t^{2} P Q}{d^{2}}
$$

$$
\begin{aligned}
& d=\text { margin of error } \\
& t=\text { corresponding to alpha } \\
& P=\text { estimated proportion of an attribute that is present in the population } \\
& Q=(1-P)
\end{aligned}
$$

Since the value of $n / N$ is 0.038 , the finite population correction (fpc) was ignored. Therefore, the effective sample included 200 males and 200 females undergraduates, who represented the young healthy population in Sri Lanka.

\subsection{Study Design}

The design of this study was a cross sectional, descriptive study. The subjects who had acute or chronic back pain, history of trauma to spine, metal implantation/internal fixation in any joints or bones, cervical problems, any other joint problems, heart diseases, recently undergone a surgery on back and abdomen, engaged in regular exercise or sports together with pregnant females and who did not give the consent to participate were excluded. The scores of well recommended and clinically proven four endurance tests were obtained in seconds. They were flexor endurance test, extensor endurance test, right side endurance test and left side endurance test. In each test, the subject was instructed to hold a particular static position for as long as possible. The test was terminated when the subject was no longer able to hold the position and time elapsed for the procedure was measured in seconds.

Two separate core stability indices were developed for males and females, based on the individual performance at four core stability endurance tests. Factor Analysis was helped to identify the pattern and the correlation between the endurance tests. Since there was a strong correlation between independent variables, the measurements decomposed to a new group of uncorrelated measurements while remaining most of the original information. Then the eigen decomposition was conducted under factor analysis to drop the eigenvalues with lower eigen-values with the aim of selecting the factors with larger eigen-values. Accordingly only one factor (Factor 1) was extracted in males and females which represents approximately $80 \%$ of the total variability of the outcomes.

\subsection{Statistical Method used in the Analysis}

\subsubsection{Independent t-test}

The independent t-test was conducted assuming equal variances in all four endurance tests to determine whether there is a significant difference of mean endurance test scores of four tests in males and females. Accordingly, mean endurance test scores for all four tests were statistically significantly different in males and females. (flexor endurance test: $P<0.05$, extensor endurance test: $P<$

\begin{tabular}{|c|c|c|c|c|c|c|}
\hline \multirow[t]{2}{*}{ Endurance tests values } & \multicolumn{3}{|c|}{ Males } & \multicolumn{3}{|c|}{ Females } \\
\hline & Mean & $\begin{array}{c}\text { Std. } \\
\text { Deviation }\end{array}$ & $\begin{array}{c}\text { Number of } \\
\text { observations }\end{array}$ & Mean & $\begin{array}{c}\text { Std. } \\
\text { Deviation }\end{array}$ & $\begin{array}{c}\text { Number of } \\
\text { observations }\end{array}$ \\
\hline Flexor endurance test value & 95.68 & 44.76 & 188 & 117.12 & 69.53 & 176 \\
\hline Extensor endurance test value & 108.14 & 44.89 & 188 & 74.94 & 39.50 & 176 \\
\hline Left Side endurance test value & 67.25 & 27.36 & 188 & 29.44 & 16.321 & 176 \\
\hline Right Side endurance test value & 64.61 & 27.97 & 188 & 29.56 & 15.86 & 176 \\
\hline
\end{tabular}
0.05 , left side endurance test: $P<0.05$, right side endurance test: $P<0.05$ ). Therefore, two different indices were constructed measure the core stability of males and females. According to the resulting descriptive outputs of four endurance tests presented in Table 1 , endurance times for the core stability tests are comparatively higher in males.

Table 1. Descriptive statistics of the sample

Figure 1 illustrates the graphical summary of correlation between four endurance tests scores. All tests are statistically significant correlated with each other $(\mathrm{p}<0.05)$. Therefore it confirms that the significant correlations exist within the predictor variables and 
further multivariate statistical methods can be conduct to study the underlying structure of these correlated endurance tests scores.

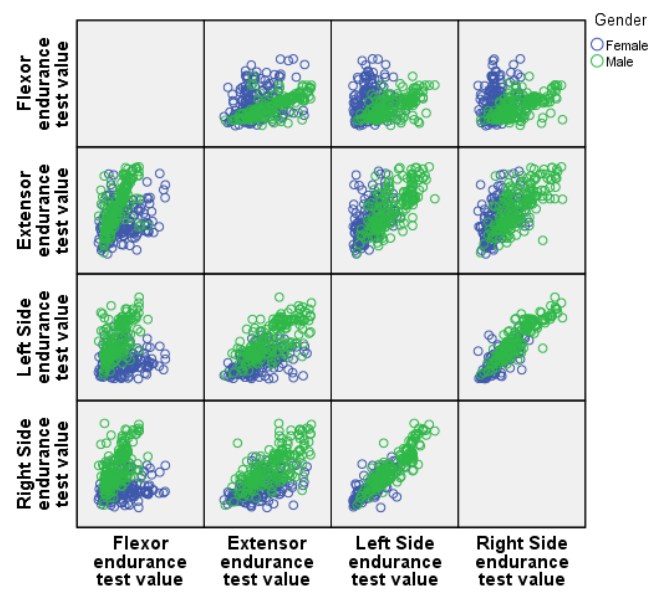

Figure1. Scatter plot matrix of endurance tests scores

\subsubsection{Factor Analysis}

Factor analysis was conducted to investigate the underlying structure of the association between the scores of four different endurance tests which are considered as the most reliable measures of the 'Core stability' of the human body. Common factors which explain most of the variance of the variables were identified. Moreover, the factor loadings for each endurance test score on common factors were calculated to detect the regression coefficients. These factor loadings can be used to predict an observed variable using common factors.

The linear composites of the endurance tests that were extracted through this multivariate statistical method, used to create a new measurement scale of core stability called as 'Core Stability Index'. Therefore, the 'Core Stability Index' was obliged to assign one value to the core stability based on combined scores obtained for four endurance tests which has a more importance rather than presenting the core stability by four different values.

As the mean values of endurance tests were statistically significantly differ in males and females, it was decided to develop two separate core stability indices for males and females. Those indices were composed of four endurance tests scores together with their corresponding coefficients.

\section{RESULTS AND DISSCUSSION}

\section{Construction of the 'Core Stability Index'}

Firstly, it was required to ensure the appropriateness of data to continue with factor analysis. According to the results presented in Table 2, data was appropriate for applying factor analysis as the calculated Kaiser-Meyer-Olkin measure of Sampling Adequacy (MSA) were 0.765 for males and 0.675 for females. Furthermore, the Bartlett's Test of Sphericity confirmed that there was an acceptable number of significant correlations among the endurance tests ( $\mathrm{p}$ value $=0.000$ ).

Table 2. Results of tests for appropriateness of the data for factor analysis

\begin{tabular}{lccc}
\hline & & Males & \multicolumn{2}{c}{ Females } \\
\hline Kaiser-Meyer-Olkin Measure of Sampling Adequacy. & .765 & .675 \\
Bartlett's Test of Sphericity & Approx. Chi-Square & 573.35 & 216.89 \\
& $\mathrm{df}$ & 6 & 6 \\
& Sig. & .000 & .000 \\
\hline
\end{tabular}

\subsection{Factor Analysis}

Afterward, the factor analysis was performed using IBM SPSS statistics 22 to determine the common factors that may adequately describe the correlation between four core stability endurance tests. 
To extract the common factors of the independent variables, two methods were used in this amongst the several methods of selecting the common factors. The first method was recommended to select the common factors which have eigen values greater than one. Accordingly, first factor were selected in both the populations as corresponding eigen values were 3.103 and 2.305 in males and females respectively. Given that, the extracted first factors (factor 1) explained 77.575 percent and 57.617 percent of the total variance of the observations in male and female populations respectively (Table 3 ).

Table 3. Total variance explained by the common factors in (a) males and (b) females

\begin{tabular}{lcccccc}
\hline & \multicolumn{3}{c}{ Initial Eigenvalues } & \multicolumn{3}{c}{ Extraction Sums of Squared Loadings } \\
Factor & Total & \% of Variance & Cumulative $\%$ & Total & $\%$ of Variance & Cumulative \% \\
\hline 1 & 3.103 & 77.575 & 77.575 & 2.827 & 70.686 & 70.686 \\
2 & .524 & 13.102 & 90.676 & & \\
3 & .271 & 6.772 & 97.448 & & \\
4 & .102 & 2.552 & 100.000 & & \\
\hline
\end{tabular}

(a)

\begin{tabular}{lcccccc}
\hline & \multicolumn{3}{c}{ Initial Eigenvalues } & \multicolumn{3}{c}{ Extraction Sums of Squared Loadings } \\
Factor & Total & \% of Variance & Cumulative \% & Total & \% of Variance & Cumulative \% \\
\hline 1 & 2.305 & 57.617 & 57.617 & 1.892 & 47.307 & 47.307 \\
2 & .901 & 22.533 & 80.150 & & & \\
3 & .540 & 13.491 & 93.642 & & \\
4 & .254 & 6.358 & 100.000 & & & \\
\hline
\end{tabular}

(b)

Scree plots that are illustrated in Figure 2, used as the second method of selecting the common factors. The scree plots also confirmed that it is worthwhile to extract one factor from each population as the number of points present above the 'elbow point' is one in both gender.

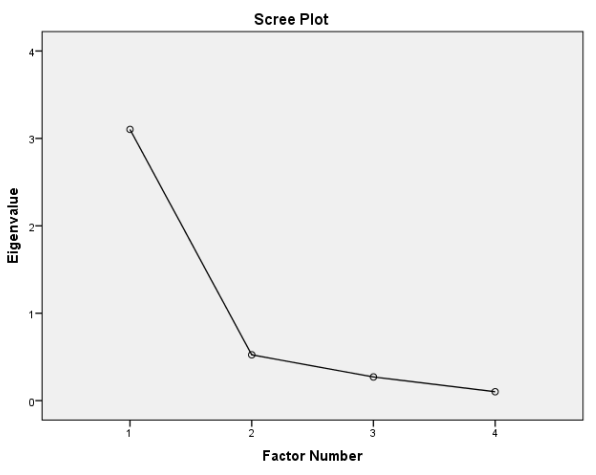

(a)

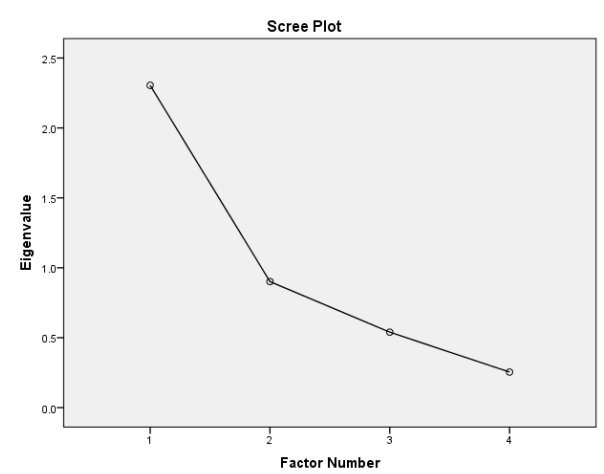

(b)

Figure 2. Scree plot of (a) Males and (b) Females

To investigate the relationship of each independent variable with the extracted factor 1, factor loadings were calculated (Table 4). These factor loadings can be interpreted as the standardized regression coefficients of the factor 1 with the endurance tests scores. When suppress the coefficients which have the values less than 0.4 , it is evident that all four test scores have strong correlations with factor 1 in males. Because as the corresponding factor loadings for left side endurance test, right side endurance test, extensor endurance test and flexor endurance test are $0.919,0.9090 .841$, and 0.735 , respectively.

Similarly, the coefficients of the factor matrix of females explain the correlation between the factors one and four endurance tests. Accordingly, there is a higher correlation between right side endurance test, left side endurance test and extensor endurance test with factor 1 , as the respective coefficients are $0.849,0.837$ and 0.639 .

Table 4. Factor matrix for endurance tests scores

\begin{tabular}{lrr}
\hline & \multicolumn{2}{c}{ Factor 1 } \\
\cline { 2 - 3 } & Males & Females \\
\hline Flexor endurance test value & .713 & .325 \\
Extensor endurance test value & .827 & .612 \\
Left Side endurance test value & .913 & .800 \\
Right Side endurance test value & .895 & .879 \\
\hline
\end{tabular}


Figure 3 illustrates the scatter plot of the first factor of the endurance test scores against the second factor (Factor 1 vs Factor 2). The pairwise separation of the different endurance test scores from this Factor 1-Factor 2 scatter plot is obvious. The figures show that flexor and extensor endurance tests scores together are influenced by the first factor while the right side and left side endurance tests scores together are mostly influenced by the second factor.

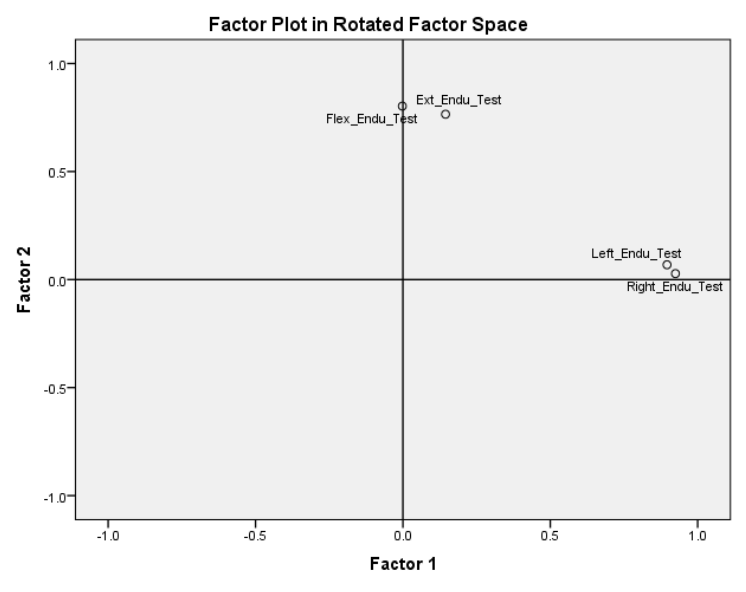

(a)

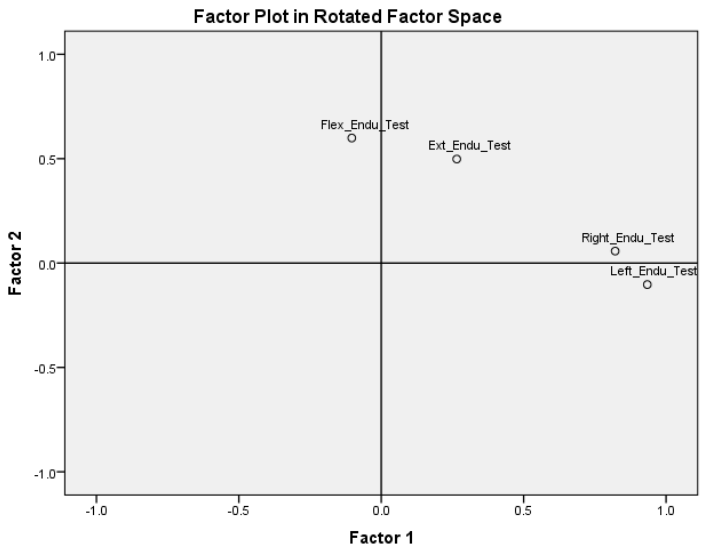

(b)

Figure 3. Factor plot of independent variables in (a) males and (b) females

It can be summarized that all endurance test scores are correlated to each other in different degrees. Because, every test measures a same property of four different muscle groups in the human body. The reason for this multicollinearity is that all independent variables measure a similar property of the muscles. Therefore, most of the variability of the sample data could be explained by factor 1. This factor can be designated as the 'Muscles endurance'.

\subsubsection{Core Stability Index}

This study proposes a single measure defining the core stability based on scores obtained for four endurance tests. This single measure can be defined as 'Core stability index'. Through this index, it can be presented one's core stability as a combined measure of four endurance tests which is quantitative and more meaningful not only to assess and understand the present situation, but also to take necessary steps in advance. Therefore, two separate core stability indices for young males and females were developed.

To obtain the coefficients of the corresponding endurance test values in the core stability index, factor scores for each endurance test were calculated (Table 5). These factor scores are regarded as. the regression scores of the index which have been obtained through a refined method to maximize the validity.

Table 5. Factor score coefficient matrix of the endurance tests

\begin{tabular}{lcc}
\hline & \multicolumn{2}{c}{ Factor score coefficients } \\
\cline { 2 - 3 } & Males & Females \\
\hline Flexor endurance test value & .126 & .072 \\
Extensor endurance test value & .258 & .168 \\
Left Side endurance test value & .401 & .292 \\
Right Side endurance test value & .282 & .559 \\
\hline
\end{tabular}

According to the coefficients obtained through the factor analysis, 'Core Stability Indices' can be defined as follows In the clinical setting, a single value representing the core stability is more desirable as the clinicians can make quick and more accurate decisions on it. Therefore, these indices can be used as a more reliable and validated tool to give a quantitative value to one's core stability as they have been constructed from the four endurance tests together with their coefficients.

Core Stability Index for Males $\quad=0.126 *$ Flex Endu Test $+0.258 *$ Ext Endu Test $+0.401 *$ Lf Endu Test $+0.282 *$ Rt Endu Test

Core Stability Index for Females $=0.072 *$ Flex Endu Test $+0.168 *$ Ext Endu Test $+0.292 *$ Lf Endu Test $+0.559 *$ Rt Endu Test

Where:

Flex Endu Test $=$ Score obtained for the flexor endurance test in seconds

Ext Endu Test $=$ Score obtained for the extensor endurance test in seconds

Lf Endu Test = Score obtained for the left side endurance test in seconds

Rt Endu Test = Score obtained for the right side endurance test in seconds

This publication is licensed under Creative Commons Attribution CC BY.

http://dx.doi.org/10.29322/IJSRP.10.06.2020.p10281

WwW.ijsrp.org 
To realize the normal value of the core stability in the young population, confidence interval was calculated based on the sample data. Accordingly, the mean value of core stability has been ranged from 80.58 seconds to 89.73 seconds in males, whereas the mean value of core stability has been ranged from 44.39 seconds to 50.27 seconds. It can be said that the mean value of core stability in females is comparatively half of the mean value of males.

Confidence interval for core stability in males $=85.14 \pm 1.96 \times 2.34=80.58-89.73$ seconds

Confidence interval for core stability in females $=47.33 \pm 1.96 \times 1.50=44.39-50.27$ seconds

Finally, the Goodness-of-fit for factor analysis models was examined by comparing the values of observed correlation with the reproduced correlations. According to the outputs present in Table 6, it is obvious that the model fits well as the elements of the residual correlation matrix are small in both genders. Moreover, the root mean square error (RMSE) was calculated as the summary measure of residual correlation matrix. Accordingly, the calculated root mean square error was 0.00031 and 0.000302 for males and females respectively. Since the root mean square errors were smaller in magnitude, it can be concluded that the above mentioned models fit well into the observations.

Table 6. Reproduced correlation matrix and residual correlation matrix for the endurance tests scores in (a) males and (b) females.

\begin{tabular}{|c|c|c|c|c|c|}
\hline & & $\begin{array}{c}\text { Flexor } \\
\text { endurance } \\
\text { test value }\end{array}$ & $\begin{array}{l}\text { Extensor } \\
\text { endurance } \\
\text { test value }\end{array}$ & $\begin{array}{l}\text { Left Side } \\
\text { endurance } \\
\text { test value }\end{array}$ & $\begin{array}{l}\text { Right Side } \\
\text { endurance } \\
\text { test value }\end{array}$ \\
\hline \multirow{4}{*}{$\begin{array}{l}\text { Reproduced } \\
\text { Correlation }\end{array}$} & Flexor endurance test value & $.642^{\mathrm{b}}$ & .701 & .601 & .586 \\
\hline & Extensor endurance test value & .701 & $.775^{\mathrm{b}}$ & .712 & .697 \\
\hline & Left Side endurance test value & .601 & .712 & $.901^{\mathrm{b}}$ & .897 \\
\hline & Right Side endurance test value & .586 & .697 & .897 & $.894^{\mathrm{b}}$ \\
\hline \multirow[t]{3}{*}{ Residual } & Flexor endurance test value & & .001 & .002 & -.002 \\
\hline & Extensor endurance test value & .001 & & -.003 & .003 \\
\hline & & $\begin{array}{c}\text { Flexor } \\
\text { endurance } \\
\text { test value }\end{array}$ & $\begin{array}{l}\text { Extensor } \\
\text { endurance } \\
\text { test value }\end{array}$ & $\begin{array}{c}\text { Left Side } \\
\text { endurance } \\
\text { test value }\end{array}$ & $\begin{array}{l}\text { Right Side } \\
\text { endurance } \\
\text { test value }\end{array}$ \\
\hline \multirow{4}{*}{$\begin{array}{l}\text { Reproduced } \\
\text { Correlation }\end{array}$} & Flexor endurance test value & $.293^{\mathrm{b}}$ & .337 & .193 & .249 \\
\hline & Extensor endurance test value & .337 & $.482^{\mathrm{b}}$ & .467 & .508 \\
\hline & Left Side endurance test value & .193 & .467 & $.765^{\mathrm{b}}$ & .742 \\
\hline & Right Side endurance test value & .249 & .508 & .742 & $.736^{\mathrm{b}}$ \\
\hline \multirow[t]{4}{*}{ Residual $^{c}$} & Flexor endurance test value & & .000 & -.002 & .002 \\
\hline & Extensor endurance test value & .000 & & .002 & -.002 \\
\hline & Left Side endurance test value & -.002 & .002 & & .000 \\
\hline & Right Side endurance test value & .002 & -.002 & .000 & \\
\hline \multirow[t]{2}{*}{ Residual } & Left Side endurance test value & .002 & -.003 & & .000 \\
\hline & Right Side endurance test value & -.002 & .003 & .000 & \\
\hline
\end{tabular}

(a) 


\section{CONCLUSONS AND RECOMMENDATIONS}

The most reliable measurement of core stability is 'Endurance', amongst the other numerous factors which contribute to build the stability of 'core' of human body. Therefore, the four endurance tests were used to assess the core stability of the subjects. As these tests are highly correlate with each other, common factors were extracted which describe the reason for this correlation. Accordingly, the principal factor of all the independent variables was 'Endurance'.

The 'Core Stability Indices' that has been constructed in this study would be a valuable tool for health care professionals to precisely and accurately measure their patients' core stability. It is quite imperative to describe the core stability by means one combined value rather than just presenting the core stability using four different values, as those four tests are correlated. Gender is one of the key determinants of the core stability in younger population. Because, the mean values of all three categories of core stability in males are significantly higher than females. The reason for this difference could be explained by the changing of muscle property in males due to the influenced of a male hormone called 'Testesteron' on muscles.

Researchers also may benefited from the developed 'Core Stability Index' as it allows to compare values across the young population which is more meaningful than concentrating on four different endurance tests values in the decision making process. The 'Scoring Scale for Core Stability' can be used to classify the individuals based on their performance at four endurance tests. According to the scoring scale, there are three categories of core stability, named as 'Lower', 'Middle' and 'Upper'. It will be more important to know the category in which the individual possess in order to make decision on it. If someone lay on the 'Lower' category, it indicates that those people should undergo a properly designed therapeutic exercise program to enhance the core stability. And for the individuals who are in other two categories should take steps to maintain their core stability without deteriorating.

It will also helpful to recognize the potential, genetically determined young individuals in the population who can be the pioneers in the sport field as the endurance is considered as one of key factors for determining the physical fitness. A further study could be designed to develop the 'Core Stability Index' and 'Core Stability Scoring Scale' that can be applicable to the whole populations addressing age, gender, health status, ethnicity and other relevant factors as this study was aimed only at the young healthy population in Sri Lanka.

The two concepts of core stability that have been emerged through this study could be generalized to the world population with the aim of improving quality of life of the people and reduce the burden on society.

\section{ACKNOWLEDGMENT}

In the accomplishment of this study successfully, supervisors, undergraduate and postgraduate colleagues and beloved family have supported me in many ways and it would not have been possible without the kind support and cooperation of them. Therefore, many thanks would be extended to my colleagues for permitting and encouraging me to accomplish the directed study as well.

\section{REFERENCES}

[1] Abeyasekera, S. (1995). Multivariate methods for index construction. Household Surveys in Developing and Transition Countries: Design, Implementation and Analysis. 1-21. Retrieved from http://unstats.un.org/unsd/hhsurveys/ [Accessed 20/07/2019].

[2] Akuthota, V., \& Nadler, S. F. (2004). Core strengthening - Focused Review. Archives of Physical Medicine and Rehabilitation. 85(3):86-92.

[3] McGill SM. (2002.) Low Back Disorders: Evidence-Based Prevention and Rehabilitation. Champaign, IL: Human Kinetics.

[4] McGill SM. (2010) Core assessment and Training. [Online] United States of America: Versa Press. Retrieved from http://www.HumanKinetics.com. [Accessed $14 / 08 / 2019]$.

[5] McGill SM, Childs A, and Liebenson C. (1990) Endurance times for low back stabilization exercises: clinical targets for testing and training from a normal database. Archieves of Physical Medicine and Rehabilitation. 80(8):941-4.

[6] Malwanage V.M.B.K.T., Aberathna S.W.M.I.C, Aludeniya A.D.C, Christa A.K, Isanka M.A , Kumari P.A. N, and Banneheka B.M.H.S.K. (2016).Development of a scoring scale for core stability. Peradeniya University Physiotherapy Congress.1.p.10.

[7] Srivastava, N. and Sandhu, A. (2006). Index for Measuring Child Feeding Practices. Indian Journal of Peadiatrics. 74:p. $263-268$.

\section{AUTHORS}

First Author - V.M.B.K.T.Malwanage, Lecturer (Probationary), MSc in Bio Statistics

(Reading) B.Sc in Physiotherapy, Faculty of Allied Health Sciences, University of

Peradeniya, ktmalwanage@gmail.com

Second Author - Prof.S.Samita, Senior Professor, Postgraduate Institute of Agriculture, University of Peradeniya, ssamita@pdn.ac.lk 
